\title{
Heterogenous expression of nestin in human pancreatic tissue precludes its use as an islet precursor marker
}

\author{
C N Street ${ }^{1}$, J R T Lakey ${ }^{1,2}$, K Seeberger ${ }^{1}$, L Helms ${ }^{1}$, \\ R V Rajotte ${ }^{1,3}$, A M J Shapiro ${ }^{1,2}$ and G S Korbutt ${ }^{1,2,4}$ \\ ${ }^{1}$ Surgical Medical Research Institute, University of Alberta, Edmonton, Alberta, Canada T6G 2N8 \\ ${ }^{2}$ Department of Surgery, University of Alberta, Edmonton, Alberta, Canada T6G 2N8 \\ ${ }^{3}$ Department of Medicine, University of Alberta, Edmonton, Alberta, Canada T6G 2N8 \\ ${ }^{4}$ Stem Cell Network of Canada, 451 Smyth Rd, Ottawa, Ontario, Canada K1H 8M5 \\ (Requests for offprints should be addressed to G S Korbutt; Email: korbutt@ualberta.ca)
}

\begin{abstract}
The discovery of a pancreatic adult stem cell would have significant implications for cell-based replacement therapies for type 1 diabetes mellitus. Nestin, a marker for neural precursor cells, has been suggested as a possible marker for islet progenitor cells. We have characterized the expression and localization of nestin in both the intact human pancreas and clinical human pancreatic islet grafts. Nestin was found to be expressed at different levels in the acinar component of human pancreatic biopsies depending on donor, as well as in ductal structures and islets to some degree. In islets, insulin-producing $\beta$-cells rarely co-expressed the protein, and in the ducts a small percentage $(1-2 \%)$ of cells co-expressed nestin and cytokeratin 19 (CK19) while most expressed only CK19 (90\%) or nestin (5-10\%) alone. Assessment of nestin expression in neonatal pancreatic sections revealed an increased number of isletassociated positive cells as compared with adult islets. Nestin immunoreactivity was also found in cells of the
\end{abstract}

pancreatic vasculature and mesenchyme as evidenced by co-localization with smooth muscle actin and vimentin. Samples from post-islet isolation clinical islet grafts revealed a pronounced heterogeneity in the proportion of nestin-positive cells $(<1-72 \%)$. Co-localization studies in these grafts showed that nestin is not co-expressed in endocrine cells and rarely $(<5 \%)$ with cytokeratinpositive ductal cells. However, relatively high levels of co-expression were found with acinar cells and cells expressing the mesenchymal marker vimentin. In conclusion we have shown a diffuse and variable expression of nestin in human pancreas that may be due to a number of different processes, including post-mortem tissue remodeling and cellular differentiation. For this reason nestin may not be a suitable marker solely for the identification of endocrine precursor cells in the pancreas.

Journal of Endocrinology (2004) 180, 213-225

\section{Introduction}

Recent advances in islet transplantation (Shapiro et al. 2000) for the treatment of type 1 diabetes has led to increased demand for a safe, abundant supply of insulinproducing tissue. This is an important goal, as presently it often requires islets from two donors to treat a patient using the Edmonton protocol, thus limiting the number of recipients for this procedure (Shapiro et al. 2000, Ryan et al. 2001, 2002). Research has focused on identifying a pancreatic stem cell or islet precursor cell that could be expanded in vitro and subsequently differentiated into functional islets. Several possible mechanisms for islet neogenesis have been proposed. These include differentiation from cells residing in the ductal epithelium (Wang et al. 1995, Bonner-Weir et al. 2000), transdifferentiation of acinar tissue (Bouwens 1998, Lipsett \& Finegood 2002, Rooman et al. 2002) and participation of other cell populations expressing specific markers of primitive or undifferentiated cells; for example pancreatic small cells (Petropavlovskaia \& Rosenberg 2002) or cells expressing the protein nestin (Zulewski et al. 2001, Abraham et al. 2002).

Nestin is an intermediate filament protein involved in cytoskeletal formation as well as cellular rearrangement to facilitate processes characteristic of undifferentiated cells, such as migration and mitosis (Palm et al. 2000, Rietze et al. 2001). It has also been demonstrated that nestin is a cellular marker for multipotent cells in the adult nervous system that can give rise to several neural lineages (Steinert et al. 1999, Messam et al. 2000, Roy et al. 2000, Sahlgren et al. 2001). Nestin-positive cells have been identified in 
murine (Hunziker \& Stein 2000), rat (Zulewski et al. 2001, Lardon et al. 2002) and human (Abraham et al. 2002) islets and evidence suggests that these cells can be induced to differentiate into islet endocrine cells (Zulewski et al. 2001, Abraham et al. 2002). Controversy, however, exists over the significance of nestin-expressing cells in islet neogenesis. Some studies report that nestin is not expressed in pancreatic epithelium, but rather in mesenchymal cells (Hanley 2002, Lardon et al. 2002, Selander \& Edlund 2002, Klein et al. 2003) and thereby suggest that the protein does not play a role in islet development. In contrast, other studies show nestin immunoreactivity in rat pancreatic ductal cells (Zulewski et al. 2001) and indicate that these are islet precursors. In addition, most studies to date have been restricted to the assessment of nestin expression in the rodent pancreas with few examining its presence in the human pancreas. Therefore, in this study we examined nestin expression within neonatal and adult human pancreatic biopsies to determine the localization of these cells. Moreover, we also evaluated whether nestin-positive cells were present in clinical human islet grafts and assessed its co-localization with other pancreatic cell phenotypes.

\section{Materials and Methods}

\section{Pancreatic biopsies and islet isolation}

Human pancreases were procured with informed research consent from donors by the University of Alberta Clinical Islet Transplant Program. Before collagenase digestion of the pancreas, two biopsies were dissected from the head region of the organ and either immediately snap-frozen at $-196{ }^{\circ} \mathrm{C}$ and stored at $-80{ }^{\circ} \mathrm{C}$ for subsequent RNA extraction or fixed in Z-fix (Anatech Ltd, Battle Creek, MI, USA). The pancreas was subsequently processed for islet isolation according to the protocols described previously by this laboratory (Lakey et al. 1999, Shapiro et al. 2000). Briefly, organs were perfused via the duct with the enzyme solution Liberase (Roche) and once digested, islets were purified on continuous Ficoll gradients using a refrigerated Cobe 2991 (COBE BCT Inc., Lakewood, CA, USA) and assessed for purity by staining with dithizone. Post-mortem neonatal pancreas sections were obtained from the Department of Laboratory Medicine (Anatomical Pathology), University of Alberta Hospital. All protocols used in this study were approved by the Research Ethics Board of the University of Alberta.

\section{$R N A$ preparation and PCR for nestin}

For frozen tissue biopsies, samples were individually freeze-ground with a mortar and pestle in liquid nitrogen $\left(-196^{\circ} \mathrm{C}\right)$ and RNA was extracted on Qiagen columns according to the manufacturer's protocol (Qiagen Inc.,
Ontario, Canada). Frozen samples of isolated islet preparations were resuspended in $1 \mathrm{ml}$ trizol reagent (Gibco/ Invitrogen) and RNA extracted according to the manufacturer's protocol. cDNA was synthesized from $1 \mu \mathrm{g}$ mRNA with 10 units $(200 \mathrm{U} / \mu \mathrm{l})$ Superscript reverse transcriptase $(\mathrm{RT})$ in $1 \times$ buffer containing $0.01 \mathrm{M}$ dithiothreitol (DTT), $0.5 \mathrm{mM}$ dNTPs and $0.02 \mu \mathrm{g} / \mu \mathrm{l}$ oligo deoxythymidine 15 (dT15). For each sample, $2 \mu \mathrm{l}$ of cDNA were used per $25 \mu \mathrm{l}$ reaction along with $1 \times$ PCR buffer, $2 \mathrm{mM} \mathrm{MgCl}, 0 \cdot 2 \mathrm{mM}$ dNTPs, 1 unit taq polymerase $(5 \mathrm{U} / \mu \mathrm{l}$ ) and $0.5 \mu \mathrm{M}$ of each primer pair (all chemicals/reagents purchased from Gibco/Invitrogen). For PCR reactions, 35 cycles were performed, with $30 \mathrm{~s}$ denaturation at $94{ }^{\circ} \mathrm{C}, 30 \mathrm{~s}$ annealing at $58{ }^{\circ} \mathrm{C}$ and $30 \mathrm{~s}$ extension at $72{ }^{\circ} \mathrm{C}$. Final polymerization was at $72{ }^{\circ} \mathrm{C}$ for $10 \mathrm{~min}$ followed by a $4{ }^{\circ} \mathrm{C}$ hold. Products were separated on a $2 \%$ agarose gel and images were captured on Alpha Digidoc software (Perkin-Elmer, Boston, MA, USA). For RT-PCR on all samples tested, two different primer sets were used to confirm positive results for nestin mRNA. Primer sequences for a $496 \mathrm{bp}$ fragment of the human nestin gene were obtained from Habener et al. (Zulewski et al. 2001) and were as follows: 5'-AGAGGGGAATT CCTGGAG-3' (sense) and 5'-CTGAGGACCAGGAC TCTCTA-3' (antisense). In addition, utilizing a different sense strand (5'-ATGAACGGGCTGGAGCAGTCTGA GGAAAGT- $3^{\prime}$ ) with the same antisense strand from Zulewski et al. (2001), a 195 bp fragment of the human nestin gene was produced from the same samples. RTPCR for human $\beta-2$ microglobulin (5'-CCAGCAGA GAATGGAAAGTC-3' sense and $5^{\prime}$-GATGCTGC TTACATGTCTCG-3' antisense) was used to verify RNA/cDNA integrity as well as to show the absence of genomic DNA contamination, as only a $268 \mathrm{bp}$ fragment was seen upon gel visualization and not the $900 \mathrm{bp}$ genomic version of the gene. All PCR products were sequenced and confirmed using a TOPO TA cloning kit (Invitrogen) and blast search against known GenBank sequences (accession numbers: X65964 for human nestin and NM_004048 for human $\beta-2$ microglobulin). The ED283 cell line (a gift from Dr Anita Gainer, University of Alberta, Edmonton, Canada) was used as a positive control for nestin mRNA. Negative controls consisted of human cDNA known not to contain the nestin gene (Applied Biosystems, Foster City, CA, USA) and $\mathrm{H}_{2} \mathrm{O}$ in place of experimental cDNA.

\section{Immunohistochemical analysis}

Pancreatic biopsies fixed in Z-fix were processed, embedded in paraffin and $3 \mu \mathrm{m}$ sections were cut and placed on to histobond slides (Marienfeld, Germany). Intact islet preparations were dissociated into single cells by mechanical disruption with a pasteur pipette at $37^{\circ} \mathrm{C}$ in $\mathrm{Ca}^{2+}$-free media supplemented with $1 \mathrm{mM}$ EGTA and $0.5 \%$ BSA for $7 \mathrm{~min}$ before addition of trypsin $(25 \mu \mathrm{g} / \mathrm{ml})$ and 
DNAse $(4 \mu \mathrm{g} / \mathrm{ml})$, and further pipetting for $4 \mathrm{~min}$. Cells were then allowed to adhere to the histobond slides and were fixed in Bouin's fixative for $12 \mathrm{~min}$ before storage at $4{ }^{\circ} \mathrm{C}$ in $70 \%$ ethanol. Immunostaining of single-cell and paraffin-embedded sections was performed using both the ABC-DAB (Avidin-Biotin Complex visualized with 3,3 diaminobenzidine) and indirect immunofluorescence methods. Sections or cells were quenched with a $20 \%$ $\mathrm{H}_{2} \mathrm{O}_{2} / 80 \%$ methanol solution. Microwave antigen retrieval was performed for $15 \mathrm{~min}$ on high power (Sanyo, $1260 \mathrm{~W}$ ) in $800 \mathrm{ml} 10 \mathrm{mM}$ sodium citrate solution (pH 6.0) for paraffin sections or $6 \times 5 \mathrm{~s}$ in $50 \mathrm{ml} 10 \mathrm{mM}$ sodium citrate for cell samples. Blocking was performed with 20\% normal goat serum (Fisher) for 15 min. Primary antibody concentrations were as follows: 1:200 polyclonal rabbit anti-human nestin 331-B (gift from Dr Conrad Messam, NINDS, NIH Bethesda, MD); 1:1000 guineapig anti-porcine insulin (Dako, Denmark); 1:200 rabbit anti-human amylase (Sigma); 1:50 mouse anti-human smooth muscle alpha-actin (Dako); 1:100 mouse antivimentin (Dako) and 1:50 mouse anti-human cytokeratin 19 (CK19) (Dako). Primary antibody incubations were $30 \mathrm{~min}$ at room temperature followed by washing (three times) with PBS before addition of secondary antibody. For amylase staining in cell samples, biotinylated secondary antibody was goat anti-rabbit obtained from Vector Laboratories (Burlingame, CA, USA) and used at a concentration of 1:200 for $20 \mathrm{~min}$ at room temperature. ABC complex (Vector) incubation time was $40 \mathrm{~min}$ at room temperature and visualization was with the chromagen diaminobenzadine (Biogenex, San Ramon, CA, USA) for $5 \mathrm{~min}$. For indirect immunofluorescence, secondary antibodies were: 1:200 Cy3-conjugated donkey anti-mouse, 1:200 fluorescein isothiocyanate (FITC)-conjugated goat anti-guinea-pig, and 1:200 Cy3-conjugated goat antirabbit (Jackson Immunoresearch Laboratories Inc., West Grove, PA, USA). Double staining was performed in sequential order for both double immunofluorescence and $\mathrm{ABC}-\mathrm{DAB} /$ fluorescence. For double staining using nestin and amylase antibodies in dissociated cell samples, stripping with $0.01 \mathrm{M} \mathrm{HCl}$ was performed between addition of primary antibodies to remove excess/unbound antibody and prevent non-specific staining (University of Alberta Histology Department, Kin et al. 2002). Negative controls for nestin immunostaining were performed using rabbit pre-immune serum also provided by Dr Conrad Messam. Negative controls for all other antibodies were performed by deletion of the primary antibody during the staining protocol. Slides were coverslipped with either Vectashield (Vector) or entellan (EM Science, Gibbstown, NJ, USA). Images were captured on a Zeiss Axioskop II fluorescent microscope with a Coolsnap camera and IP lab software (Scanalytics Inc., Fairfax, VA, USA). Single cell counts were performed on a minimum of 500 cells per sample and percentages were calculated as the number of positives per 500 .

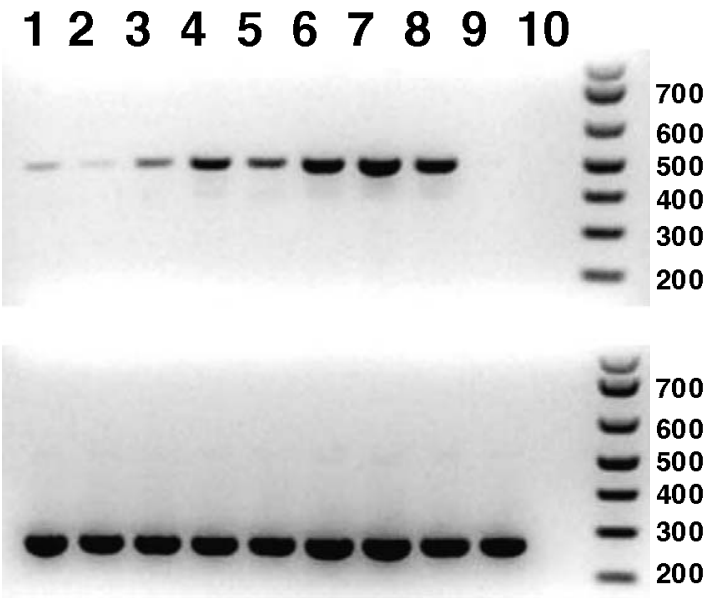

Figure 1 (Top) RT-PCR for a 496 bp fragment of human nestin mRNA in five pancreatic biopsies prior to islet isolation (lanes 1-5) and in two different isolated islet preparations (lanes 6 and 7). The ED283C glioblastoma cell line was used as a positive control for human nestin (lane 8 ) and negative controls consisted of human control cDNA (lane 9) and $\mathrm{H}_{2} \mathrm{O}$ in place of experimental cDNA (lane 10). (Bottom) RT-PCR on the same samples as above for human $\beta-2$ microglobulin to verify RNA/cDNA integrity.

\section{Statistical analysis}

Values are expressed as means \pm S.D. Statistical significance of differences was calculated by a one-way ANOVA and Scheffe's test. Linear analysis of correlations was calculated using Pearson's correlation coefficient and all tests were performed on Statview (SAS Institute Inc., Cary, NC, USA). All significance levels were set at $P<0 \cdot 05$.

\section{Results}

Nestin $m R N A$ expression in human pancreatic biopsies and isolated islets

We initially used RT-PCR to analyze RNA isolated from five different adult pancreatic biopsies collected prior to islet isolation in order to confirm expression of nestin mRNA. In Fig. 1 (lanes 1-5) a 496 bp fragment was detected in five of the five biopsies tested using primers previously described for the human nestin gene (Zulewski et al. 2001). A different primer set giving a $195 \mathrm{bp}$ fragment was also used to confirm this result (data not shown, see Materials and Methods). Subsequent isolation of both fragments and sequencing confirmed this product to be human nestin. Nestin mRNA was also detected in two isolated human islet preparations (Fig. 1, lanes 6 and 7), thereby indicating that cells having the potential to express nestin are retained during the islet isolation procedure. A human glioblastoma cell line was used as a 

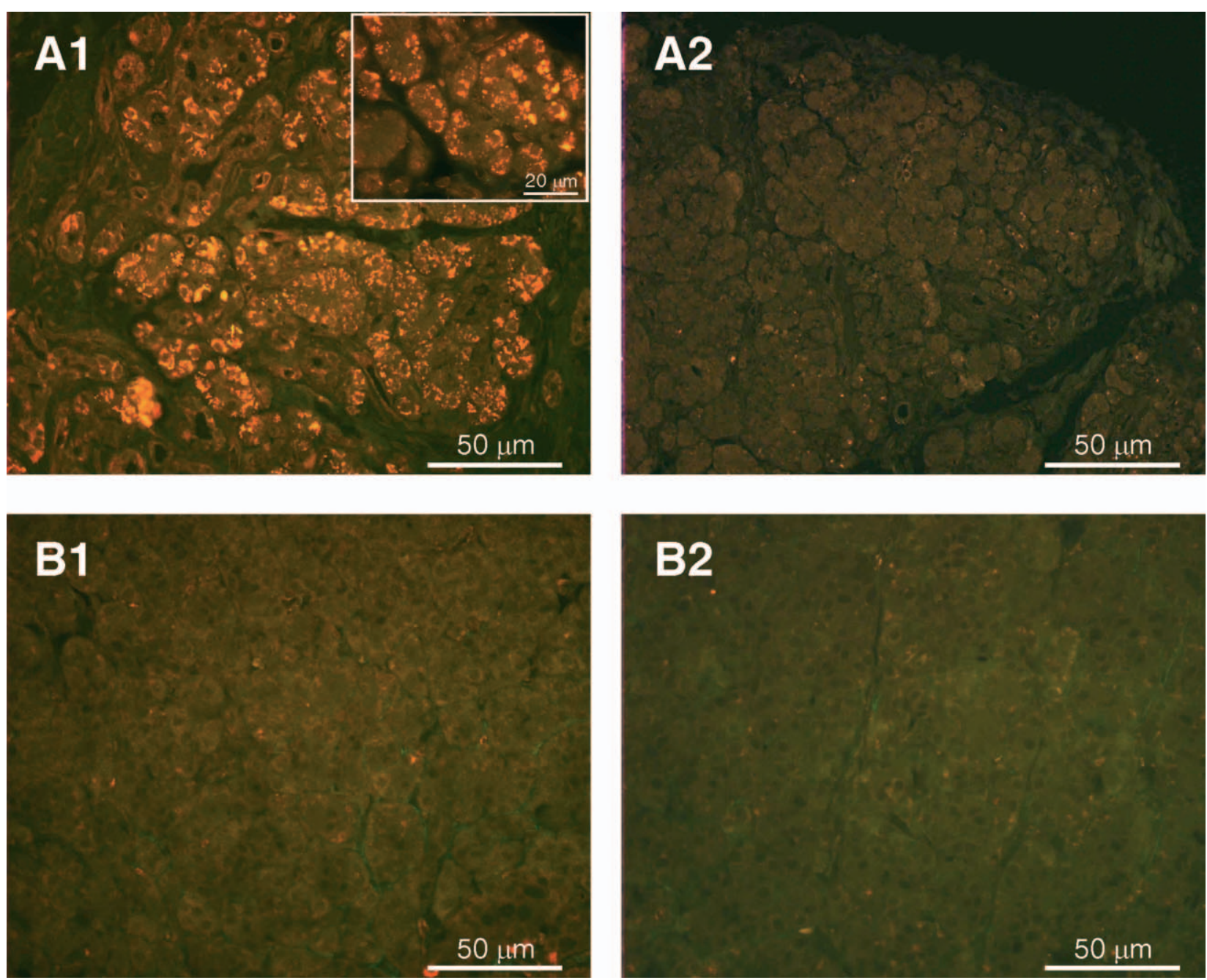

Figure 2 Localization of nestin-positive cells in the acinar component of human pancreatic sections. Nestin was found to be highly expressed in some organs (A1; negative control for nestin A2) while much lower in others (B1; negative control for nestin B2).

positive control for nestin RT-PCR (lane 8) and negative control reactions using human control cDNA (lane 9) and $\mathrm{H} 2 \mathrm{O}$ (lane 10) showed the absence of the nestin gene product.

\section{Nestin localization in human acinar pancreas}

Immunohistochemical staining of human pancreatic sections $(n=15)$ revealed a diffuse and variable pattern of nestin expression among different donors. Some pancreases exhibited high levels of nestin expression while others were shown to be significantly lower (Fig. 2). Differences in the abundance of nestin-positive cells between donor organs were largely due to the relative presence or absence of nestin immunoreactivity in acinar tissue. Extensive nestin staining was present in the acinar lobules of some organs (Fig. 2A1 and A2) while virtually absent in others (Fig. 2B1 and B2). Comparisons of all biopsies analyzed revealed a range of nestin expression in acinar tissue from very little $(<1 \%)$ to extensive $(\sim 30 \%)$ with 11 biopsies expressing the protein in $10 \%$ or more of the cells in a given section and four biopsies expressing the protein in less than $10 \%$ of the section. In order to assess more accurately the co-localization of nestin with acinar cells we examined dissociated single-cell suspensions prepared from clinical islet preparations. These samples were found to contain $34 \cdot 7 \pm 16 \cdot 1 \%$ amylase-positive cells, while 40 $50 \%$ of the cells expressing nestin also stained positive for amylase (Fig. 3A and B). The arrows on Fig. 3A1 and A2 demonstrate cells expressing both nestin and amylase (arrow A), amylase but not nestin (arrow B), and nestin but not amylase (arrow C). 

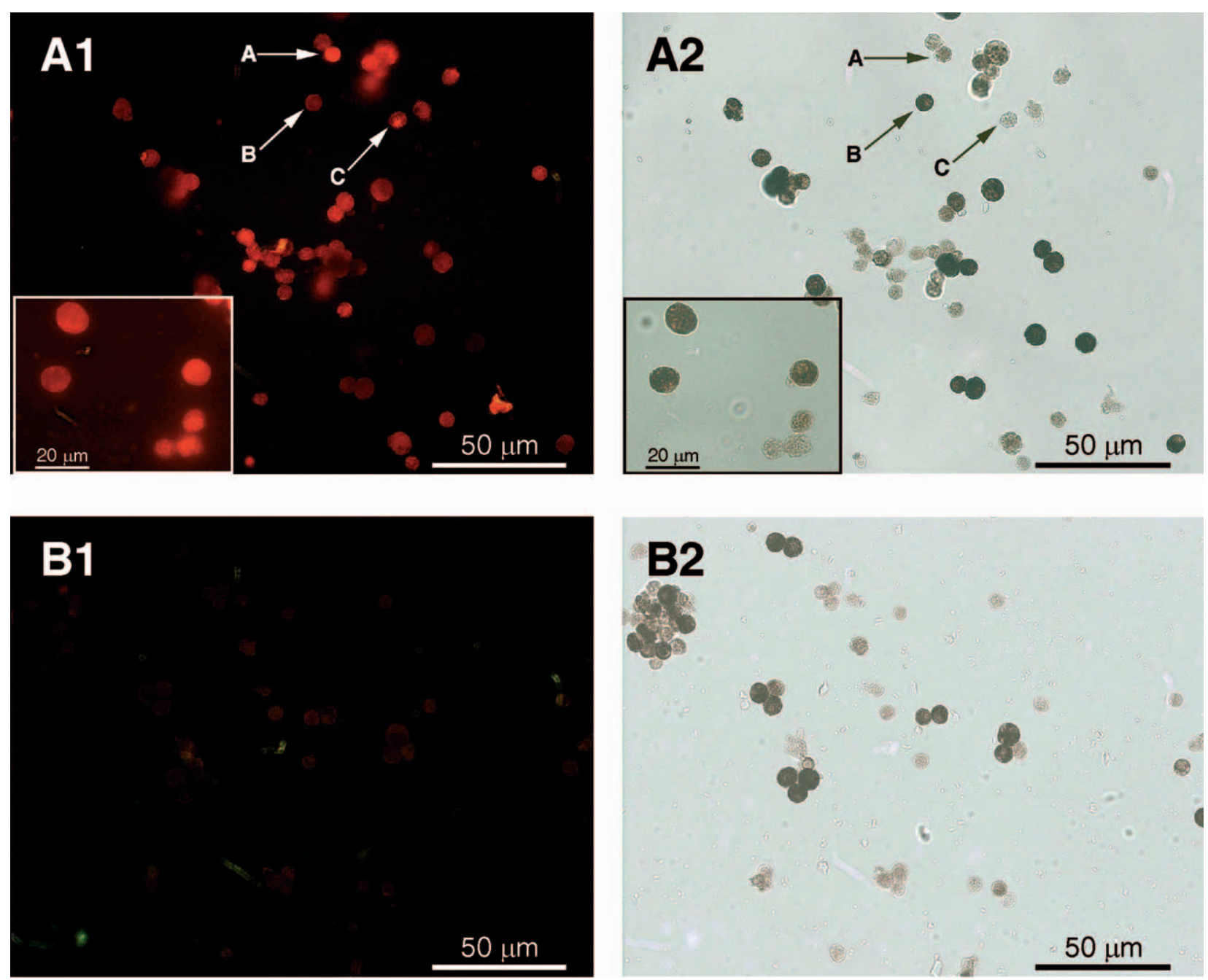

Figure 3 Co-localization of nestin- and amylase-expressing exocrine cells in dissociated clinical human islet grafts. (A1 and A2) Same field of cells showing nestin staining (A1, Cy3) and amylase staining (A2, brown color). Arrows indicate cells expressing both nestin and amylase (arrow A), amylase alone (arrow B), or nestin alone (arrow C). (B1 and B2) Same field of cells showing the negative control for nestin using pre-immune serum (B1) and amylase staining (B2).

\section{Nestin expression in pancreatic ducts}

Nestin-positive cells were observed to be infrequently associated with both small (Fig. 4B1 and B2) and larger (Fig. 4A1 and A2) pancreatic ducts, although these cells typically did not express CK19 (Fig. 4A1, inset) whereas the majority of cells within the ducts did. However, in some sections, a small proportion of cells were found to express both nestin and CK19 (arrow, Fig. 4B1). Analysis of dissociated clinical islet preparations revealed similar results whereby only a small percentage of cells co-expressed both nestin and CK19 (<1\%) (Fig. 4C1, inset) while a greater proportion expressed either CK19 alone $(23 \cdot 8 \pm 11 \cdot 9 \%)$ or only nestin $(16 \cdot 6 \pm 13 \cdot 7 \%)$. Figure 4C1 and C2 shows staining for CK19 and nestin by dual-immunofluorescence.
Nestin expression in islets

Nestin-positive cells were also detected within the majority of islets examined in intact adult pancreatic sections (Fig. 5). These cells comprised a small percentage of the islet mass (Fig. 5A1 and A2) and co-localization of nestin and insulin was rarely observed, indicating that nestin is not normally expressed in the mature $\beta$-cell. However, in one pancreatic biopsy, nestin was shown to be co-expressed with insulin (arrow in Fig. 5B1 and Fig. 5B2) and these rare double-positive cells were usually observed in small clusters of $\beta$-cells or as single $\beta$-cells. Despite this exception, close examination of dissociated clinical islet grafts showed that in almost all cases the nestin-expressing cells $(16 \cdot 6 \pm 13 \cdot 7 \%)$ did not co-localize with insulin in mature $\beta$-cells $(23 \cdot 4 \pm 11 \cdot 9 \%)$ (Fig. 5C1 and C2). 

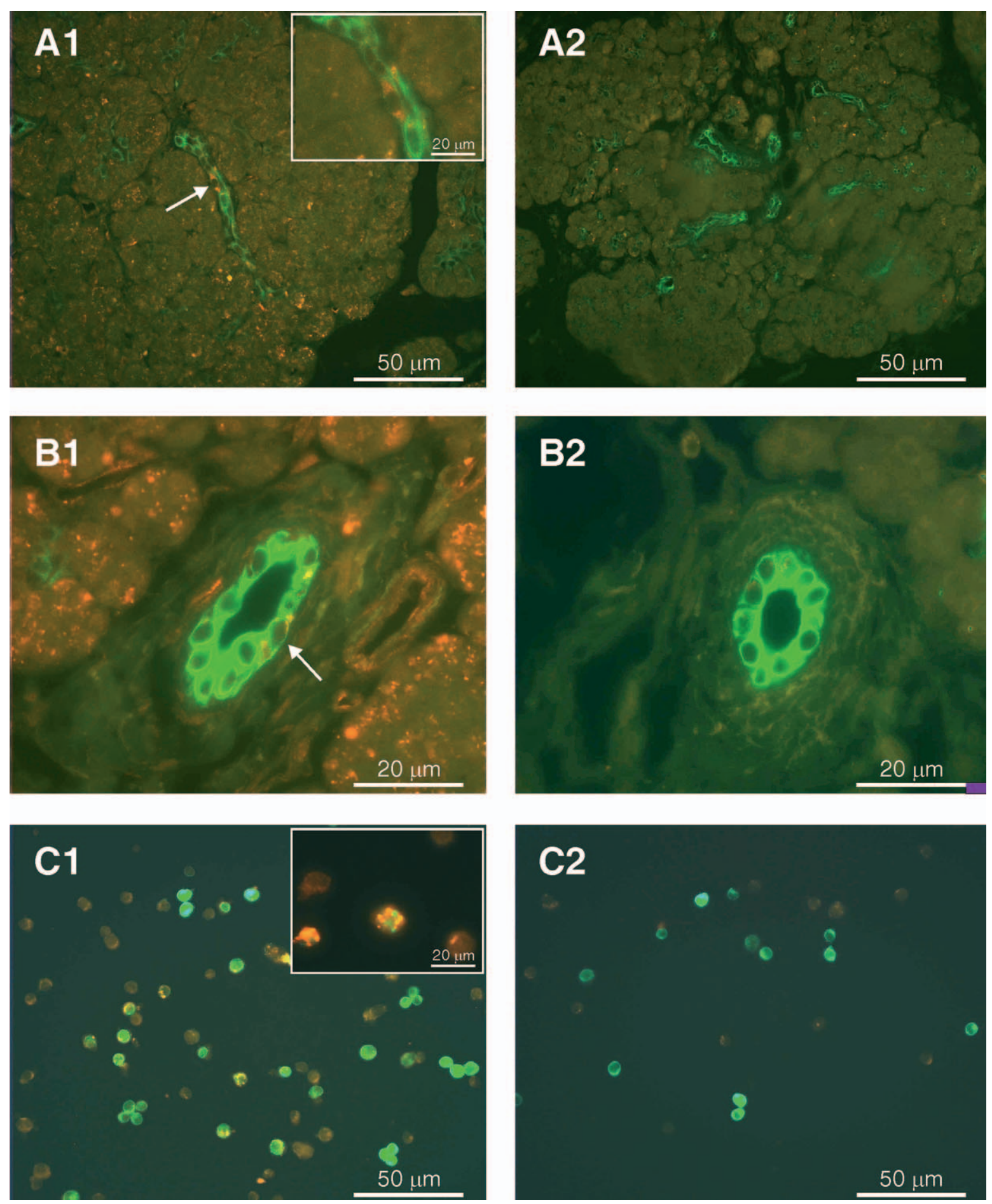

Figure 4 Co-localization of nestin (Cy3) and CK19 (FITC) in human pancreatic ducts and dissociated ductal cells. (A1 and A2) Staining for nestin and CK19 in larger ductal structures. Inset indicates a cell within the duct expressing nestin but not CK19. (B1 and B2) Staining for nestin and CK19 in small duct structures. Arrow indicates a CK19-positive ductal cell co-expressing nestin. (C1 and C2) Double staining for CK19 and nestin in a dissociated human pancreatic cell sample. Inset indicates a cell expressing both markers. A2, B2 and C2 depict corresponding negative controls for nestin immunostaining using pre-immune serum and regular staining for CK19 to show ductal structures. 

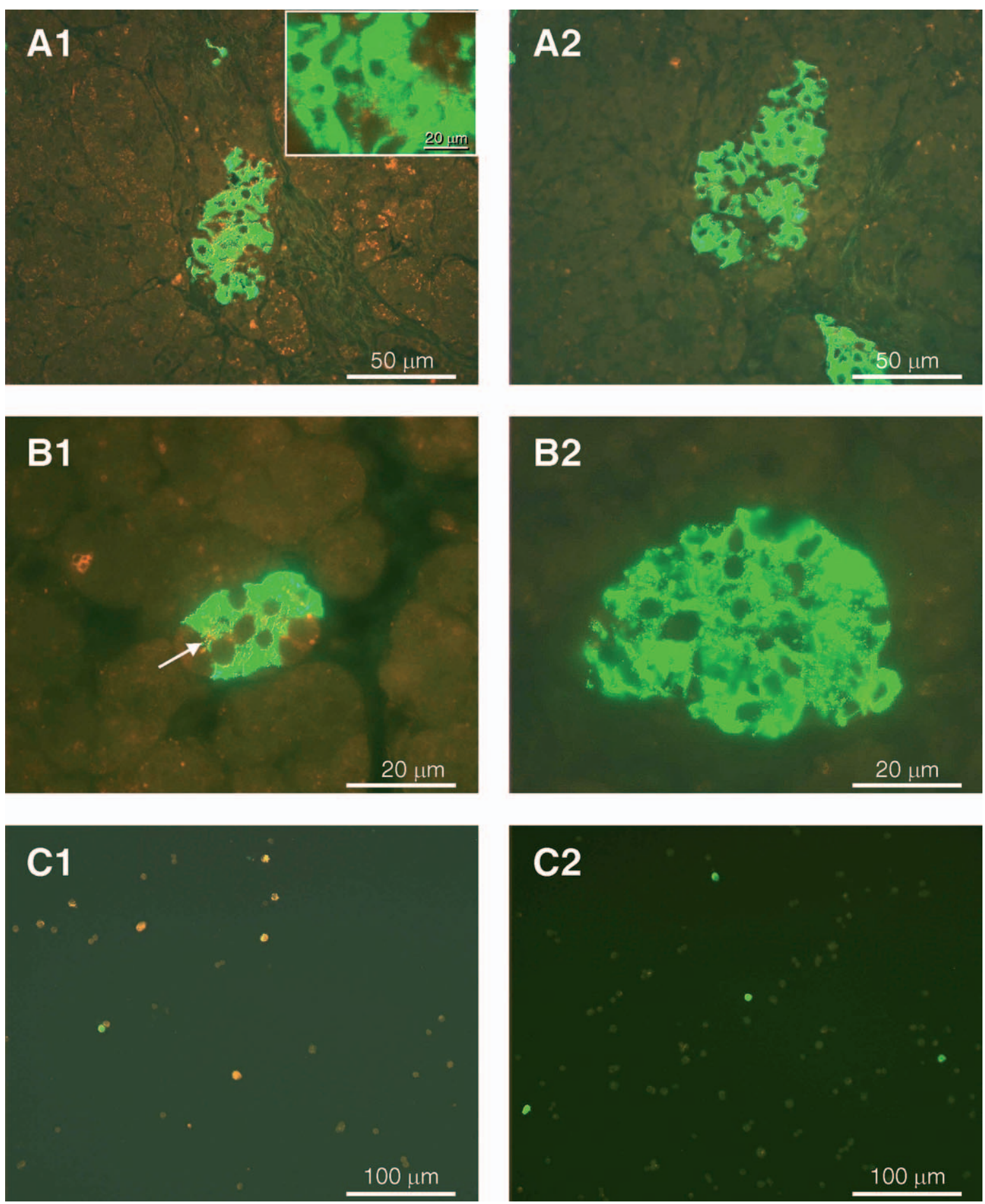

Figure 5 Nestin expression in human pancreatic islet sections and dissociated islet preparations. (A1 and A2) Staining for insulin (FITC) and nestin (Cy3) in an adult pancreatic section indicates frequent intra-islet expression but no co-localization of nestin in $\beta$-cells. (B1 and B2) In rare circumstances, however, insulin and nestin were co-expressed in cells of some small islets (arrow). (C1 and C2) Double staining in dissociated islet cell preparations for insulin (FITC) and nestin (Cy3) revealed no co-localization of nestin in insulin-positive cells in these grafts. A2, B2 and C2 depict corresponding negative controls for nestin immunostaining using pre-immune serum and regular staining for insulin to show pancreatic islets. 
Nestin expression in pancreatic vasculature and mesenchymal cells

Several reports have described nestin expression in the pancreatic vasculature and in cells of mesenchymal origin; we therefore further examined nestin expression patterns within the pancreas. Smooth muscle actin was used to identify blood vessels in human pancreatic sections, and our previous experiments demonstrated that CK19positive pancreatic ductal epithelium does not stain positive for smooth muscle actin (data not shown). Figure 6A1 and A2 illustrates characteristic smooth muscle actin staining in large blood vessels in the adult pancreas. Both large and small blood vessels expressed smooth muscle actin ubiquitously, and cells of these structures were often but not always shown to co-express nestin (Fig. 6A1, inset). No cells expressing smooth muscle actin were observed in dissociated human islet preparations and thus co-localization with nestin was not observed in these samples. Using vimentin as a marker for mesenchymal cells, nestin expression was also assessed in the mesenchymal component of the human pancreas (Fig. 6B, C and D). Nestin expression was frequently observed in intact cellular structures staining positive for vimentin (Fig. 6B1 and $\mathrm{C} 1$, insets), along with single expression of one or the other marker in the same structures. Furthermore, immunostaining of dissociated pancreatic cell preparations showed frequent co-expression of nestin and vimentin (Fig. 6D1 and D2 and inset). In the human islet preparations assessed, about $20 \%$ of the cells staining positive for nestin also expressed vimentin.

\section{Nestin expression in neonatal human pancreas}

In order to predict whether nestin plays a role in pancreatic or islet development, expression was also assessed in whole pancreatic sections derived from a neonatal human pancreas. Staining in these sections revealed a pattern similar to the adult, whereby nestin-expressing cells were found associated with the acinar tissue in and near some ductal structures, blood vessels, mesenchymal cells and also in most islets. One striking difference was the pattern and abundance of staining in the neonatal islets. The neonatal human islets contained significantly more nestin-positive cells compared with adult islets, often localized around the mantle of the islet as well as interspersed through the center (Fig. 7). Figure 7A1 and A2 shows nestin expression in several neonatal islets and Fig. 7B1 and B2 depicts a typical pattern of nestin staining in a neonatal islet at high magnification $(\times 1000)$. No insulin/nestin co-expressing cells were observed in the neonatal islets despite this increase in nestin expression.

\section{Nestin-expressing cells in human clinical islet grafts}

Immunostaining and quantification of dissociated samples from clinical islet grafts showed a large amount of variation in proportion of nestin-positive cells. Grafts $(n=48)$ were analyzed retrospectively and characterized as being $23 \cdot 4 \pm 11 \cdot 9 \% \quad \beta$-cells, $9 \cdot 2 \pm 6 \cdot 2 \%$ alpha-cells, $23 \cdot 8 \pm$ $11.9 \%$ ductal and $34 \cdot 7 \pm 16 \cdot 1 \%$ acinar cells. These grafts were found to have a mean of $16 \cdot 6 \pm 13 \cdot 7 \%$ nestinpositive cells with a range of $0 \cdot 5-72 \%$. This variability between preparations did not correlate with factors such as donor age, gender, body mass, period of cold ischemia prior to islet isolation, or the collagenase digestion time. Similarly, the proportion of nestin-positive cells also did not correlate with measures of isolation success such as islet equivalents recovered per gram of pancreas, islet preparation purity and glucose-stimulated insulin secretion.

\section{Discussion}

The discovery and subsequent isolation of a pancreatic stem cell or islet precursor cell would represent an important step towards the production of an unlimited islet supply for transplantation to type 1 diabetics. Although islet neogenesis has been described in adult pancreatic tissue (Dudek et al. 1991, Bouwens \& Pipeleers 1998, Rooman et al. 2002), a consensus has not been reached on the specific identity or phenotype of the precursor cells involved. Recently, attention has focused on the protein nestin as a possible marker for a population of cells in the pancreas that may have the ability to differentiate into endocrine cells (Hunziker \& Stein 2000, Zulewski et al. 2001, Abraham et al. 2002, Lechner et al. 2002). We have characterized the expression of nestin in the adult and neonatal human pancreas, as well as in dissociated human pancreatic islet cell grafts, with special attention to its co-localization with other pancreatic cell types. Furthermore, we have defined differences in expression and localization patterns depending on the donor pancreas whereby some organs express relatively high levels of nestin and others relatively low.

RT-PCR analysis detected nestin mRNA in five of five pancreatic biopsies as well as two post-isolation islet preparations. This finding confirms the potential for nestin expression in cells of the human pancreas, and led us to analyze specific localization of the protein using immunostaining of human pancreatic sections and dissociated pancreatic cell samples.

Analysis of multiple sections from human pancreatic biopsies revealed a variable pattern of nestin expression between donors. In particular, some donor pancreases had very high levels of nestin expression while others were very low. Although the possibility cannot be ruled out that expression varies in different regions of the pancreas, our reproducibility of results in multiple sections from each pancreas, and the fact that the biopsy was consistently removed from the same area of the head of the organ suggests that an inherent difference exists in expression 

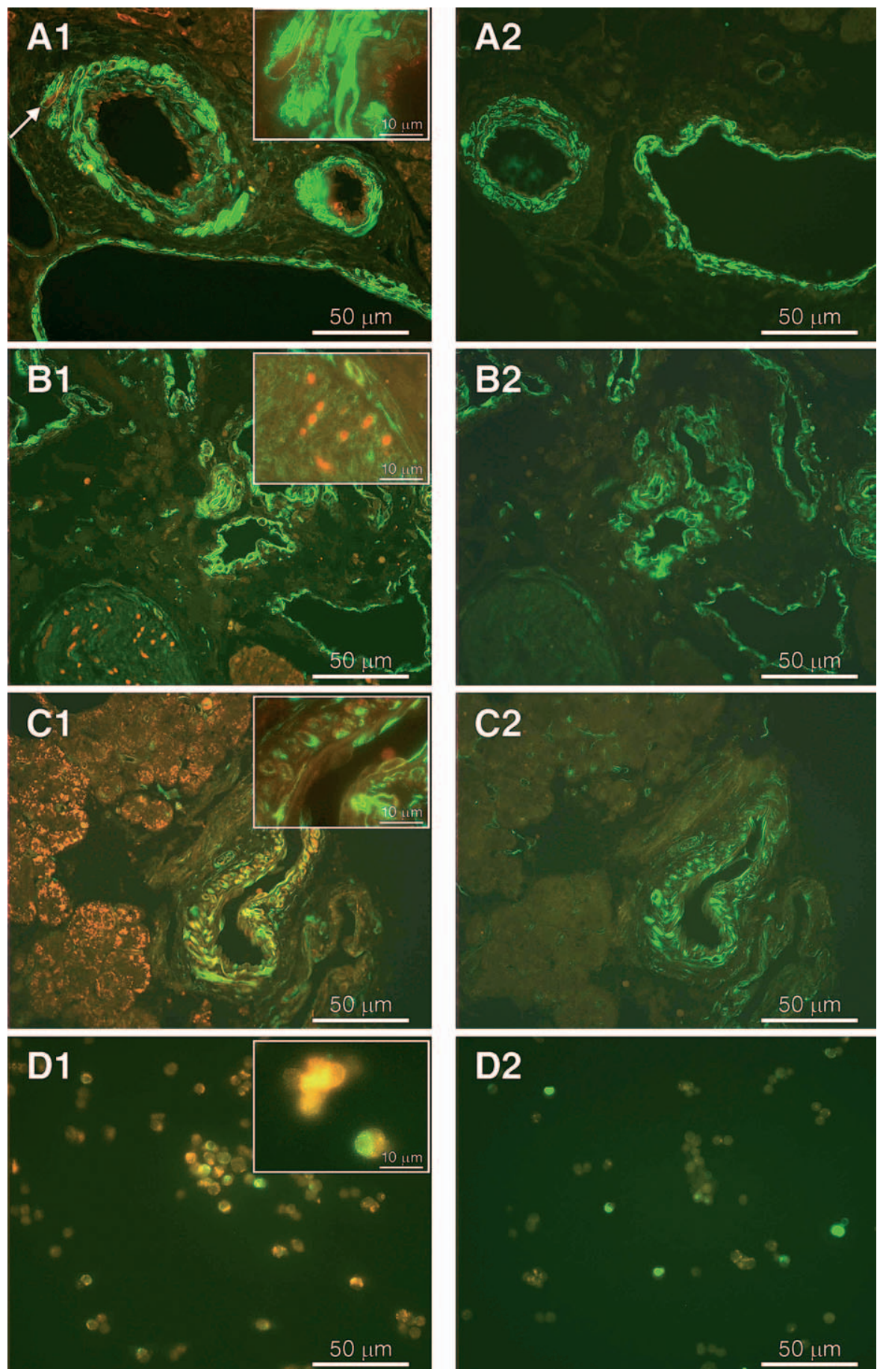

Figure 6 Nestin expression associated with pancreatic vasculature and mesenchyme-derived cells. (A1 and A2) Nestin (Cy3) and smooth muscle alpha-actin (FITC) staining shows nestin expression in vasculature-associated cells. Inset indicates a double-positive cell. (B1, B2, C1 and C2) Nestin (Cy3) and vimentin (FITC) staining shows frequent co-expression of both markers in vimentin-expressing mesenchymal structures. Insets indicate double-positive cells. (D1 and D2) Staining for nestin (Cy3) and vimentin (FITC) in dissociated pancreatic cell preparations also shows frequent co-localization of the two markers. A2, B2, C2 and D2 depict corresponding negative controls for nestin immunostaining using pre-immune serum and regular staining for smooth muscle actin/vimentin to show vasculature and mesenchymal cells. 

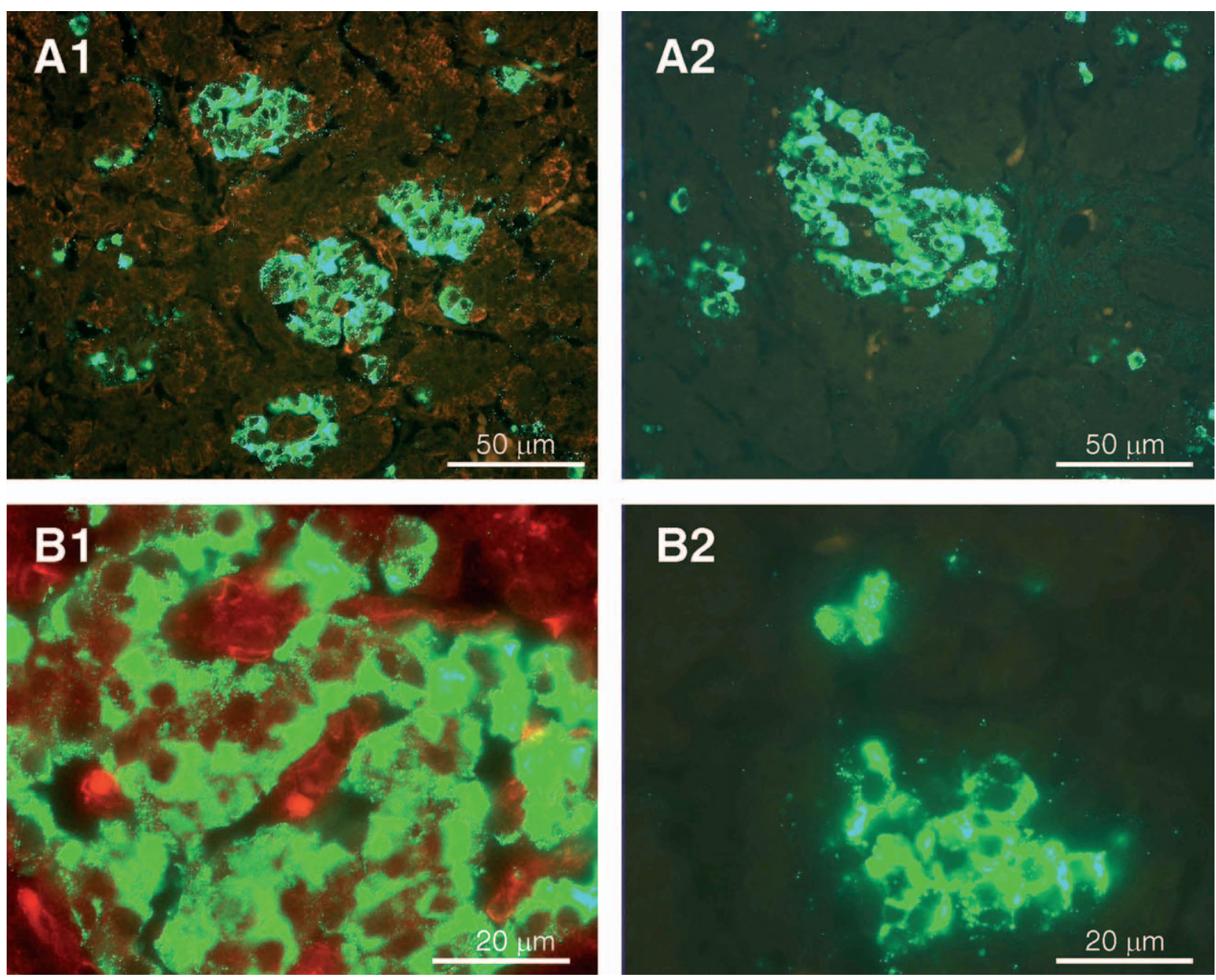

Figure 7 Nestin localization in islets of the neonatal human pancreas. (A1 and A2) Immunostaining for insulin (FITC) and nestin (Cy3) at lower magnification $(\times 400)$ shows extensive nestin expression in neonatal pancreatic islets. (B1 and B2) Same staining at high magnification $(\times 1000)$ shows a high proportion of nestin-expressing cells in a neonatal islet interspersed with insulin-producing $\beta$-cells. $\mathrm{A} 2$ and $\mathrm{B} 2$ depict corresponding negative controls for nestin immunostaining using pre-immune serum and regular staining for insulin to show pancreatic islets.

levels between donors. Furthermore, using double staining in dissociated pancreatic preparations, it was observed that $40-50 \%$ of the cells expressing nestin were amylasepositive acinar cells. In these preparations, a correlation was noted between the proportion of acinar cells expressing nestin and the levels of nestin expression seen in corresponding intact biopsies. To our knowledge this is the first report of nestin expression in pancreatic acinar cells. Moreover, since nestin-positive cells were observed in islets as well as in ductal structures with approximately the same frequency regardless of donor, and expression levels varied widely in the acinar component, this suggests that donor variation depends largely on expression in acinar cells.
Nestin expression in cells of the ductal epithelium may suggest a possible role in islet neogenesis, as it is widely believed that the birth of new endocrine cells in the mature pancreas occurs via differentiation of ductal cells (Dudek et al. 1991, Wang et al. 1995, Bouwens \& Pipeleers 1998, Bonner-Weir et al. 2000). Our findings agree with Habener and co-workers (Zulewski et al. 2001) in the rat pancreas whereby scattered nestin-positive cells were found in both large and small ductal structures. In contrast to that study, however, where it is reported that no nestin-positive cells co-express the ductal marker CK19, our results show a small percentage of cells $(1-2 \%)$ in the human pancreas that do express both markers. This discrepancy can most probably be attributed to 
species-specific differences. Our results therefore suggest at least three phenotypically distinct cell populations within the human pancreatic ducts. Most abundant are the $\mathrm{CK} 19^{+} /$nestin $^{-}$cells that comprise the majority of cells in the ductal structure (90\%). Also present are the $\mathrm{CK}_{19^{-}}$/ nestin $^{+}$cells that occur at a lower frequency $(5-10 \%)$ and finally the $\mathrm{CK} 19^{+} /$nestin $^{+}$cells which are rare $(1-2 \%)$ and are not found in most ductal structures.

Previous studies have reported the presence of nestinpositive cells within islets themselves. Hunziker and Stein (1998) showed the presence of nestin-expressing cells in mouse islets while Habener and co-workers isolated these cells from both rat (Zulewski et al. 2001) and human (Abraham et al. 2002) islet cultures. All of these studies fail to show the co-localization of nestin and insulin, suggesting that nestin is not expressed in the mature $\beta$-cell. Our results in whole human pancreas conflict with these reports as, in rare circumstances, nestin was found to be co-expressed in insulin-producing cells. These doublepositive cells were often observed in small clusters of $\beta$-cells randomly distributed throughout the pancreas. It is possible that these nestin-positive $\beta$-cells are the initiation of newly forming islets, since extra-islet endocrine cells have previously been suggested to be indicators of islet neogenesis in pancreatic regeneration models $(\mathrm{Xu}$ et al. 1999). The fact that no nestin-expressing $\beta$-cells were observed in clinical islet grafts using immunohistochemistry is most probably due to the rarity of these cells or to the destruction of these smaller islet structures during collagenase digestion of the organ.

It has been proposed that nestin-positive cells found in the rat and human pancreas are not of endodermal origin but are in fact vasculature cells or other cells of mesenchymal origin (Lardon et al. 2002, Klein et al. 2003). Our analysis of human pancreatic sections support these findings in part, as nestin was shown to be frequently co-localized in blood vessels of both exocrine and endocrine compartments. Since nestin is known to be involved in cellular remodeling processes (Palm et al. 2000, Rietze et al. 2001), and we observed that not all vasculature contained nestin-expressing cells, this implies that remodeling of circulatory pathways may be constantly occurring in some areas of the pancreas in response to changing dynamics between endocrine/exocrine cells.

Examination of neonatal or developing pancreas, as opposed to fully matured adult pancreas, may provide insight into the role of nestin in pancreatic development. For this reason nestin expression was also assessed in neonatal human pancreatic biopsies. Although expression was heterogenous in these sections as it was in the adult, surprisingly the neonatal islets contained far more nestinpositive cells than adult pancreatic islets. Selander and Edlund (2002) recently reported that nestin-positive cells in the developing mouse pancreas were not epithelial in nature and did not express any endocrine hormones or key transcription factors such as PDX-1 and thus were mes- enchymal in origin. Although we observed nestin-positive cells clearly within the islet structure itself, the vast majority of these did not express insulin or the ductal epithelial marker CK19, indicating that they may in fact be mesenchymal cells. The fact that these cells also did not co-express smooth muscle actin, however, suggests they are not part of the islet microvasculature. Interestingly, Bouwens and co-workers (2002) observed a tenfold increase in nestin-positive cells within islets of a ductligated portion of rat pancreas, where an environment of organ neogenesis is created that may be similar to fetal or neonatal development. The authors also report that these cells were found surrounding ducts and islets and proposed them to be involved in angiogenesis to support newly forming islets and exocrine tissue during regeneration. We also observed increased nestin immunoreactivity surrounding islets in the growing neonatal pancreas, and although these were not mature blood vessel endothelial cells, it cannot be ruled out that these cells may be involved in angiogenesis and are not endodermal in origin.

Quantification of immunostaining in clinical human islet grafts showed a wide range in the proportion of nestin-expressing cells $(<1-72 \%)$ with a mean of $16 \cdot 6 \pm 13 \cdot 7 \%$. This range could not be explained by comparison to donor or isolation factors such as age/organ cold ischemia time. Since these human islet grafts are not pure $(23 \cdot 4 \pm 11 \cdot 9 \% \beta$-cells), but also contain contaminating acinar cells $(34 \cdot 7 \pm 16 \cdot 1 \%$ amylase-positive), and our observations suggest that nestin is co-expressed in acinar cells, it is likely that a large proportion of nestin-positive cells in these grafts are acinar in origin. The possibility also exists that mesenchymal cells are present in these grafts as well, and may be another small source of nestin-positive cells. This was evidenced by the extensive co-localization of nestin and vimentin seen in these grafts. Further staining in clinical islet grafts gave results similar to those found in whole pancreatic sections, whereby no cells were found to co-express nestin and insulin, few cells $(<1 \%)$ co-expressed nestin and CK19, and a large proportion of cells (40-50\%) co-expressed nestin and amylase. Analysis of long-term patient outcomes may provide answers to the question of significance of nestin-expressing cells in these grafts.

In conclusion, we have shown the presence of nestinpositive cells in clinical human islet grafts and demonstrated that most of the cells in these grafts originate from the exocrine pancreas, with a small number coming from ducts and pancreatic vasculature. The data presented in this study suggest that the majority of nestin-positive cells in the human pancreas are probably not islet precursors, but rather acinar or mesenchymal cells. Some of the data we report, however, conflict with a recent study by Klein et al. (2003), which suggests that all nestin-positive cells of the human pancreas are vascular in origin. This study reports that no endocrine, acinar or duct cells express nestin and that previously reported duct-associated cells 
expressing nestin are small capillary structures and do not represent islet precursors. These differing results may be in part due to the specificities of the antisera used in the two studies. It should be noted however, that while the study by Klein et al. (2003) looked at biopsies from only two different adult pancreases, we have extensively characterized nestin expression in 15 different adult biopsies, 48 clinical human islet grafts, and one human neonatal pancreatic biopsy. Furthermore, we believe that in order to accurately assess co-localization of nestin and other pancreatic markers, it is necessary to examine single cell preparations, as it is often difficult to distinguish double staining with $100 \%$ accuracy in intact sections. However, in agreement with the Klein et al. study, we did observe that a significant proportion of vasculature-associated cells in the pancreas also express nestin. These observations suggest that nestin cannot be used in the human pancreas as an endocrine precursor cell marker. However, the fact that nestin was rarely observed in extra-islet $\beta$-cells, combined with the increased nestin expression seen in islets of the neonatal pancreas, shows that the involvement of nestin in islet neogenesis cannot be ruled out without an exhaustive assessment of all populations expressing the protein. Due to its functional role, expression does not necessarily mark a specific cell state or population, but a cellular process that may or may not indicate an involvement in islet differentiation. Isolation, comparison, and clonal analysis of nestin-positive cells from multiple areas of the pancreas will provide further insight into cellular changes in the adult organ.

\section{Acknowledgements}

The authors would like to thank Dawne Colwell for assistance with Figures and formatting as well as Lynette Elder and Sunil Parimi for technical assistance. Special thanks to Dr Conrad Messam and Dr Eugene Major for provision of the nestin 331-B antibody. We would also like to thank the staff of the Clinical Islet Laboratory (University of Alberta) for their assistance in the isolation of pancreatic islets as well as the HOPE program for the identification/procurement of organs from cadaveric donors. Cale Street is supported in part by a grant from The Stem Cell Network (Canadian Centres of Excellence). J R T L and G S K are recipients of scholarships from the Canadian Diabetes Association as well as the Alberta Heritage Foundation for Medical Research. G S K also has a Career Development Award from the Juvenile Diabetes Research Foundation International. A M J S is a Clinical Investigator of the Alberta Heritage Foundation for Medical Research and holds the Clinical Research Chair in Transplantation (CIHR/Wyeth).

\section{Funding}

Funding for the Clinical Islet Laboratory is provided through grants from the Alberta Foundation for Diabetes
Research, the Juvenile Diabetes Foundation and the Medical Research Council. The authors have no conflicts of interest that would prejudice the impartiality of this manuscript.

\section{References}

Abraham EG, Leech CA, Lin JC, Zulewski H \& Habener JF 2002 Insulinotropic hormone glucagons-like peptide 1 differentiation of human pancreatic islet derived progenitor cells into insulin producing cells. Endocrinology 143 3152-3161.

Bonner-Weir S, Taneja M, Weir GC, Tatarkiewicz K, Song K, Sharma A \& O'Neil JJ 2000 In vitro cultivation of human islets from expanded ductal tissue. PNAS 97 7999-8004.

Bouwens L 1998 Transdifferentiation vs. stem cell hypothesis for the regeneration of islet beta-cells in the pancreas. Microscopy Research and Technique 43 332-336.

Bouwens L \& Pipeleers DG 1998 Extra-insular beta cells associated with ductules are frequent in adult human pancreas. Diabetologia 41 629-633.

Dudek RW, Lawrence IE, Hill RS \& Johnson RC 1991 Induction of islet cytodifferentiation by fetal mesenchyme in adult pancreatic ductal epithelium. Diabetes 40 1041-1048.

Hanley NA 2002 Beta cell differentiation during human development does not rely on nestin positive precursors: implications for stem cell derived replacement therapy. Diabetologia 45 1045-1047 (letter).

Hunziker E \& Stein M 2000 Nestin expressing cells in the pancreatic islets of Langerhans. Biochemical and Biophysical Research Communications 271 116-119.

Kin T, Rajotte RV, Dufour JM \& Korbutt GS 2002 Development of an immunoprivileged site to prolong islet allograft survival. Cell Transplantation 11 547-552.

Klein T, Ling Z, Heimberg H, Madsen OD, Heller RS \& Serup P 2003 Nestin is expressed in vascular endothelial cells in the adult human pancreas. Journal of Histochemistry and Cytochemistry $\mathbf{5 1}$ 697-706.

Lakey JRT, Warnock GL, Shapiro AMJ, Korbutt GS, Ao Z, Kneteman NM \& Rajotte RV 1999 Intraductal collagenase delivery into the human pancreas using syringe loading or controlled perfusion. Cell Transplantation 8 285-292.

Lardon J, Rooman I \& Bouwens L 2002 Nestin expression in pancreatic stellate cells and angiogenic endothelial cells. Histochemistry and Cell Biology 117 535-540.

Lechner A, Leech CA, Abraham EJ, Nolan AL \& Habener JF 2002 Nestin positive progenitor cells derived from adult human pancreatic islets of Langerhans contain side population (SP) cells defined by expression of the ABCG2 (BCRP1) ATP-binding cassette transporter. Biochemical and Biophysical Research Communications 293 670-674.

Lipsett M \& Finegood DT $2002 \beta$-cell neogenesis during prolonged hyperglycemia in rats. Diabetes 51 1834-1841.

Messam CA, Hou J \& Major EO 2000 Coexpression of nestin in neural and glial cells in the developing human CNS defined by a human specific anti nestin antibody. Experimental Neurology 161 585-596.

Palm K, Salin-Nordstrom T, Levesque MF \& Neuman T 2000 Fetal and adult human CNS stem cells have similar molecular characteristics and developmental potential. Molecular Brain Research 78 192-195.

Petropavlovskaia M \& Rosenberg L 2002 Identification and characterization of small cells in the adult pancreas: potential progenitor cells? Cell and Tissue Research 310 51-58.

Rietze RL, Valcanis H, Brooker GF, Thomas T, Voss AK \& Bartlett PF 2001 Purification of a pluripotent neural stem cell from the adult mouse brain. Nature 412 736-739. 
Rooman I, Lardon J \& Bouwens L 2002 Gastrin stimulates $\beta$-cell neogenesis and increases islet mass from transdifferentiated but not from normal exocrine pancreas tissue. Diabetes 51 686-690.

Roy NS, Wang S, Jiang L, Kang J, Benraiss A, Harrison-Restelli C, Fraser RAR, Couldwell WT, Kawaguchi A, Okano H, Nedergaard M \& Goldman SA 2000 In vitro neurogenesis by progenitor cells isolated from the adult human hippocampus. Nature Medicine $\mathbf{6}$ 271-277.

Ryan EA, Lakey JRT, Rajotte RV, Korbutt GS, Kin T, Imes S, Rabinovitch A, Elliot JF, Bigam D, Kneteman NM, Warnock GL, Larsen I \& Shapiro AMJ 2001 Clinical outcomes and insulin secretion after islet transplantation with the Edmonton Protocol. Diabetes $\mathbf{5 0}$ 710-719.

Ryan EA, Lakey JRT, Paty BW, Imes S, Korbutt GS, Kneteman NM, Bigam D, Rajotte RV \& Shapiro AMJ 2002 Successful islet transplantation: Continued insulin reserve provides long term glycemic control. Diabetes 51 2148-2157.

Sahlgren CM, Mikhailov A, Hellman J, Chou Y, Lendahl U, Goldman RD \& Eriksson JE 2001 Mitotic reorganization of the intermediate filament protein nestin involves phosphorylation by cdc2 kinase. Journal of Biological Chemistry 276 16456-16463.

Selander L \& Edlund H 2002 Nestin is expressed in mesenchymal and not epithelial cells of the developing mouse pancreas. Mechanisms of Development 113 189-192.

Shapiro AMJ, Lakey JRT, Ryan EA, Korbutt GS, Toth E, Warnock GL, Kneteman NM \& Rajotte RV 2000 Islet transplantation in seven patients with type 1 diabetes mellitus using a glucocorticoid free immunosuppressive regimen. New England Journal of Medicine $343230-238$.

Steinert PM, Chou Y, Prahlad V, Parry DA, Marekov LN, Wu KC, Jang S \& Goldman RD 1999 A high molecular weight intermediate filament associated protein in BHK-21 cells is nestin, a type VI intermediate filament protein. Journal of Biological Chemistry 274 9881-9890.

Wang RN, Kloppel G \& Bouwens L 1995 Duct to islet cell differentiation and islet growth in the pancreas of duct ligated adult rats. Diabetologia 38 1405-1411.

Xu G, Stoffers DA, Habener JF \& Bonner-Weir S 1999 Exendin-4 stimulates both $\beta$-cell replication and neogenesis, resulting in increased $\beta$-cell mass and improved glucose tolerance in diabetic rats. Diabetes 48 2270-2276.

Zulewski H, Abraham EJ, Gerlach MJ, Daniel PB, Moritz W, Muller B, Vallejo M, Thomas MK \& Habener JF 2001 Multipotential nestin-positive stem cells isolated from adult pancreatic islets differentiate ex vivo into pancreatic endocrine, exocrine, and hepatic phenotypes. Diabetes 50 521-533.

Received 10 October 2003

Accepted 17 October 2003

Made available online as an

Accepted Preprint 22 October 2003 